\title{
Article
}

\section{Qualities of reflection: using Saul's (2001) On Equilibrium to restore humanity to reflection in healthcare}

\author{
Eaton, Colette
}

Available at http://clok.uclan.ac.uk/16719/

Eaton, Colette ORCID: 0000-0002-5375-344X (2017) Qualities of reflection: using Saul's (2001) On Equilibrium to restore humanity to reflection in healthcare. Reflective Practice. pp. 1-8. ISSN 1462-3943

It is advisable to refer to the publisher's version if you intend to cite from the work. http://dx.doi.org/10.1080/14623943.2016.1268116

For more information about UCLan's research in this area go to http://www.uclan.ac.uk/researchgroups/ and search for < name of research Group>.

For information about Research generally at UCLan please go to http://www.uclan.ac.uk/research/

All outputs in CLoK are protected by Intellectual Property Rights law, including Copyright law. Copyright, IPR and Moral Rights for the works on this site are retained by the individual authors and/or other copyright owners. Terms and conditions for use of this material are defined in the policies page.

\section{CLoK}

Central Lancashire online Knowledge www.clok.uclan.ac.uk

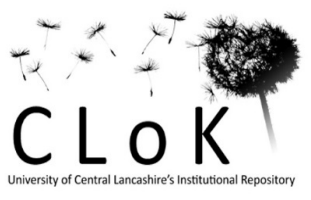




\section{Qualities of reflection: Using Saul's (2001) On Equilibrium to restore humanity to reflection in healthcare.}

\section{ABSTRACT:}

Reflection features strongly in health and care work as a tool for personal and professional development and can support us as practitioners to be critical and self-aware in practice, of practice and the impact on clients and patients. Its power to transform learning and practice however has been watered down through recipe-following in reflective recording and through the avoidance of recording uncertainty or practice that might not measure against professional codes. Drawing on the humanist philosophy of John Ralston Saul, I suggest using Saul's (2001) 'six qualities' as themes for reflective questions. I reflect on the influence of reason through codes of practice and offer suggestions for questions to restore an awareness of Self in work with clients and patients. Finally, from my experience as a counselling student and healthcare educator, I argue that we should have a greater appreciation of the power of uncertainty in reflective recording.

Keywords: reflection, reflexivity, counselling, healthcare, Saul, humanism, uncertainty

\section{Introduction}

I am a healthcare educator and trainee counsellor and this allows me to consider how learning in one discipline can be enhanced by the methods in another. Counselling practice encourages me to reflect deeply on the impact of my Self in work with others and how I work with uncertainty and I believe strongly that these are useful reflections for any people work. What triggered this article, however, is a number of seemingly unrelated events: firstly, as a registrant of the Health and Care Professions Council (HCPC) in the UK, I received the revised Standards of Conduct, Performance and Ethics (HCPC, 2016). Secondly, I am aware of colleagues preparing for the Nursing and Midwifery Council (NMC) revalidation, a process which requires all practising nurses and midwives in the UK to submit a portfolio showing competence to practise. Lastly, I was reading 'On Equilibrium' (Saul, 2001) and I wanted to explore Saul's humanist ideas as themes for reflecting on Self and the work I do with clients. The aim of this article is to show how these events have come together to create a tension worth reflecting on. 
I was introduced to the Canadian philosopher John Ralston Saul through an article considering 'On Equilibrium' and its relevance for practice development in healthcare systems (Walsh, 2007). Saul (2001) argues that the 'shape of human genius' is made up of six qualities: common sense, ethics, imagination, intuition, memory and reason. These may appear as limited and unrelated concepts however Saul states that we should acknowledge these as essential qualities having equal and universal value. Furthermore, if we fully integrate them into ordinary life, we can find equilibrium and a more human existence. Saul goes on to argue that over-reliance on one ('reason' for example) can lead to a distrust or disregard for another ('intuition') leaving us, as individuals and in groups, feeling powerless and incapable of acting for change. Walsh (2007) in his very accessible article, identifies where these qualities could work in practice development to ensure that process and systems do not overshadow the humanness of healthcare. Having used these qualities as themes for critically questioning the holism in my counselling practice, I wondered if they could be used in reflection for healthcare practice.

\section{Thinking, reflecting and reflexivity}

Reflective thought was defined by Dewey (1933:7) as "Active, persistent and careful consideration of any belief or supposed form of knowledge in the light of the grounds that support it, and the further conclusions to which it tends." It pushes the individual to consciously question why and how she thinks, believes, accepts and understands leading to further knowledge. During the 1980's reflection became not only a cornerstone of personal development for practitioners of people work but also a radical and emancipatory strategy for questioning the power of professional knowledge (Schön, 1983), and the broader social, political and cultural influences impacting on professional decision making (Nelson, 2012).

Teaching and learning in reflective practice is still central to social work, counselling and nursing: as the 'pearl grit in the oyster of practice and education' (Bolton, 2014:1) reflective thinking should still be producing curious enquirers in people work. Unfortunately, for Nelson (2012) this emancipatory quality has been lost due to a watering down of the political basis for reflection. Schön's (1983) clear aim for reflective practice was to question the dominance of the technical-rational in learning, yet in health care, reflective writing is 
increasingly used for assessing of competence, with clear penalties for failing to adhere to regulatory models of writing (Coward, 2011: Nelson, 2012). It feels like the educational value of reflective thinking is becoming increasingly lost in poor educational practice and 'recipe-following' in reflective writing. (Boud \& Walker, 1998)

A real strength of reflective thinking is that it openly values doubt and uncertainty and encourages the learner to make her own meaning through questioning and experience (Boud, 1999). Supporting practitioners to struggle with uncertainty and to consciously question the nature of systems and actions is vital for the 'double-loop' of reflection and reflexivity (Schön \& Argyris, 1974). Learning and practice by their nature are permeated by social, political and cultural influences and consequently difficult to participate in objectively (Boud \& Walker, 1998). In healthcare, engaging in critical reflection on the impact of those influences encourages us to look for fairer and more humanised systems and strategies. Mezirow (1997:10) argues that for any new learning to be significant, it must be incorporated into a well-established "symbolic frame of reference", however we must continually question the assumptions at the heart of that frame of reference. This ensures that we start to think for ourselves, rather than simply acting on the learning and concepts of others (Mezirow, 1998). Reflexivity, therefore is an inherently political standpoint which should examine the why's of practice within the personal and social context of its existence and should seek to bring the humanness of people work to the centre of what we do. It follows then that the reflexive practitioner recognises the cultural and social assumptions embedded in her agency's policies and procedures (Boud \& Walker, 1998) and will regularly explore if these are right for each client.

\section{Reflection in Practice}

There is little doubt that reflecting, and learning from reflection, are still key elements in training in health and care practice. My nursing colleagues are encouraged to view revalidation as '... the opportunity to reflect on the role of the Code in your practice as a nurse or midwife ..." and a means of encouraging "a culture of sharing, reflection and improvement;" (NMC, 2015:5). As a trainee counsellor, I am expected to submit reflective accounts in order to apply to the register of accredited practitioners (BACP, 2014) and as evidence of continuing professional development for my registration as a social worker in 
the UK. The reflective learning here is solidly rooted in expectations of development in practice.

Reflective recording in practice is changing however. The templates offered by NMC for validation ask only four questions (see table 1) suggesting nurses measure their reflective learning against the Code of Practice. Whilst I accept that Codes offered by registering bodies are ostensibly benevolent and useful guides, by Mezirow's definition, they are still frames of reference. As these Codes are increasingly used as measures of competence, it feels risky for practitioners to critically question the systems, environment and political influences through which the Codes develop. There is tension between being accountable to organisational demands, and being honest and genuine about what we do not know in order to learn from it (Fook \& Askeland, 2007). Furthermore, we are moving away from reflecting on emotions or even mistakes which are rich in opportunities for learning about Self (Berman, 2001). It is unlikely that nurses or midwives would risk their validation by recording where their practice falls short of standards or where they are overwhelmed by work in increasingly challenging environments. Templates like these can guide practitioners to become simply 'accountable recorders' of events showing fitness for practice rather than examining the humanity in healthcare. This is not the emancipatory, transformative learning from reflection envisaged by Schön and Mezirow.

\section{Table 1.}

What was the nature of the CPD activity and/or practice-related feedback and/or event or experience in your practice?

What did you learn from the CPD activity and/or feedback and/or event or experience in your practice?

How did you change or improve your practice as a result?

How is this relevant to the Code?

Select one or more themes: Prioritise people - Practise effectively - Preserve safety Promote professionalism and trust

(Nursing and Midwifery Council, 2015) 
From my own experience I appreciate that true critical reflection is a frightening task. This is truly 'risky writing' (Berman, 2001) and leaves me open to questions about my competency and proficiency. I would argue however that it is a rare and occasionally dangerous state to be certain of our work with people and by asking ourselves the right questions we uncover what we do not know (Bourner, 2003; Moon, 2004) in order to learn from it. Using Saul's (2001) qualities as themes in my own reflective questioning helps me work with this uncertainty in counselling and gives me a deeper sense of my Self in relation to my client. I suggest that their use in nursing and healthcare might help reflective thinking return to supporting critical self-awareness in those professions. What follows is a brief exploration of each of the qualities and suggestions for questions that could be asked.

\section{Reason}

In his book, Saul (2001) explores reason last but here it feels right for me to tackle it first and examine its influence in Codes governing healthcare practice. Saul argues that society regards reason as a virtuous, objective and ethical force, untouched by the muddy uncertainty of imagination and intuition. In healthcare, reason would have us practice always "...on the best evidence available..." (NMC, 2015:7) Reason, without other qualities as counterbalance, can become ideology and limits critique of the political and social influences on the generation of that best evidence. Furthermore, reason presented as detailed instructions for practice and the increasing reification of values such as compassion and empathy can effectively remove human decision making from healthcare; for example, the HCPC (2016: 9) insists that I '...must be honest and open when something has gone wrong...' and offers reassurance that it does not regard an apology as '...an admission of liability...' (HCPC, 2016:12). I would hope that any apology comes from my honest consideration of the rights and wrongs of personal action and I wonder why, as a human being, I would need the comfort of certainty written into a Code. To start my reflection then, I can examine professional guidance and protocol and its political context. I can ask whether I am anxious about getting it right by standards rather than considering the impact of me on my client. I can also consider which procedures I use simply because they make the system work and whether this alienates the client (Walsh, 2007). Powerfully, I could ask 
'If the client was me what would she practice by and why?' I am not advocating that we abandon reason but we need to explore its origin, purpose and impact in practice.

\section{Common Sense}

Common sense is an overly used and almost diminished concept which Saul (2001) reinstates to its original meaning of 'shared knowledge'. Even with our skills in analysis and expertise, we do not fully understand all we do as practitioners (Schön, 1983) and a reflective practitioner often tries to make sense of her action and reaction through a shared knowledge of 'good practice'. Undoubtedly, this knowledge is informed by the reason contained in policies and guidelines. Using common sense however, we can acknowledge that practitioners and patients have many of the same experiences; birth, death, loneliness, sickness and health, but may have very different understandings of these existential realities. Common sense has the power to connect us to a patient or client in a way that makes us aware of the implications of our interventions andcan encourage us to consider the differences in our understanding of that work. It can make the difference between competent, technical care and humanised care (Scammell, 2015). During reflection, I can ask what common sense I share with the client around their current experiences, the meaning of my interventions and how these might affect our work together. Balanced with other qualities such as ethics, imagination and reason, I suggest that reflecting on this common sense of practice and experience highlights the power of working with, rather than on, the client.

\section{Ethics}

Ethics is like a muscle which must be exercised daily in order to function, Saul (2001) argues and he laments the fact that we have almost structured ethics out of our daily awareness. He suggests that real human ethics is the complex process of each individual making in the moment decisions about what living a good life means. In health and care work, we often attempt to rectify unacceptable practice by explicitly revisiting codes of ethics, practice guidelines and mission statements to offer professional certainty. In the UK, for example, the Francis Report (2010) on the failings of the Mid Staffordshire Hospital Trust raised uncomfortable questions about values in patient care. One of the responses from the healthcare profession was the 6 ' $C$ 's of compassionate nursing (DH, 2012) which laid out the 
values deemed necessary in practice. Despite acknowledgment that "No statement of ethics can eliminate the difficulty of making professional judgements..." (BACP, 2015:4) our decisions in practice are measured against these statements leaving limited room for our own measurement of self in 'good' care. Using Saul's (2001) concept, I can carefully consider what 'good' I did with and for the client or patient and who that 'good' is for. I can also explore the harm I might do to the client and to recognise that even our most benevolent interventions may bring about a loss of some kind for her or others. With imagination and reason, I can examine our common sense of 'good' and 'harm' and consider how working to the Code might affect our connection. Saul (2001) goes on to caution that to be rigorous in exercising the ethics muscle means I should be prepared to question any answers that arise.

\section{Imagination}

For Saul (2001), this is a quality that energises the norm. It is very easy in reflection, as in practice, to follow a rote of thinking and acting that is familiar and safe. Imagination is a freeing quality and allows me to conceive of the other; what would it be like to be the patient or client and what I might do and feel and be in her position. Imagination has a dynamic power and can open a wealth of creative possibilities but these can be stifled in healthcare practice due to an increasing need for hard evidence or cautious adherence to procedures. As Rolfe (2014) suggests, most practitioners can demonstrate competent care but, as in the case of Mid Staffs, sometimes lack “...the imagination and the empathic understanding to see the need for it." (Rolfe, 2014:1460) During reflection I can employ imagination to consider what I might do if I was the patient and what I might do after meeting me. I can also consider what she might imagine about me, in work, outside work and about the experience of working together. This, with common sense and memory, encourages me to critically examine the inherent power differentials in our positions as practitioner and client. Furthermore, I can imagine, then negotiate, more equal and empathic ways of working. 


\section{Intuition}

Provocatively, Saul (2001) defines intuition as a defence reaction to our need to choose how to act and how to express ourselves. Occasionally, we will make decisions based on reason, memory and common sense and we use imagination to help us manage the uncertainties and potential consequences of the decision. Frequently though, Saul argues, we make a choice, hoping it is right, and this is intuition. Saul suggests that this is the quality most affected by the dominance of reason and that we have almost lost our trust of its power. Despite growing interest in intuition in nursing (Hassani, Abdi \& Jalali, 2016), it rarely features as a way of knowing in reflective templates and we are required to rationalise any intuitive choices through analysis, and application of theory and research. To be fully human in practice I cannot ignore my gut feeling about my client and her issues and the felt sense I use to make choices about my interventions in her care. I should carefully question what felt right, what left me with a sense of wrong, and what might be the client's intuitive sense of our work together.

\section{Memory}

Saul (2001) argues that memory shapes our past and experience and we use it daily to form our present and future. He explains that memory gives us context and a rational framework to thinking and action located in other more shapeless qualities of common sense, imagination, ethics and intuition. Used well, memory helps us guards against fossilised practice or adherence to a rigid ideology, and can protect against the loss of self in work with people. Saul suggests that our memory of any experience marks us as separate from others thus reinforcing a sense of Self, but at the same time, it connects us to a common sense of existence. Reflection is not just recalling an event to learn from it. I can consolidate this learning with my memory of similar experiences and their outcomes. I can also question strategies that have worked in the past and those I might need to avoid. Importantly, I can consider past events and social, cultural and political influences that the client might also be remembering and how these might impact on the work that we do, or that we steer away from. I can ask which memories separate me from the client and which might contribute to our common sense of experience.

\section{On reflecting}


This article has attempted to apply Saul's (2001) ideas of the qualities of human genius to reflecting on work with clients in healthcare. I have suggested that this philosophical framework helps locate the Self in practice and identifying the human genius in people work. My experience of writing reflectively using these qualities is not always comfortable but Saul is very clear in his assertion that to be human is to welcome the tension of seeking equilibrium through the push and pull of each quality. It has not always provided answers but the uncertainty I have experienced has acted as the 'pearl grit' for me to question why I am and what I represent with each client. The qualities push me to question if I practice with a common sense of our humanity and to examine what is good and creative for us. Furthermore, I examine whether my strongest connection is with my client or with the Codes and procedures that govern my practice. The questions I have proposed can help counter the dominance of reason through professional standards and ways of recording and help restore a humanised framework for reflective practice and reflexivity in healthcare. As an educator, I am bound to defer to reason by testing this framework with students and practitioners and any outcomes will be examined in future articles. My task now is to ensure that testing reason is balanced with common sense, ethics, imagination, intuition, and memory.

\section{References}

Berman, J. (2001) Risky writing: Self-disclosure and self-transformation in the classroom. USA: University of Massachusetts Press.

Bolton, G. (2014) Reflective practice: Writing and professional development. $4^{\text {th }}$ Edn. London, UK: SAGE Publications

Boud, D. \& Walker, D. (1998) Promoting reflection in professional courses: The challenge of context. Studies in Higher Education. June 98, 23:2, 191-207

Boud, D. (1999) Avoiding the traps: seeking good practice in the use of self-assessment and reflection in professional courses. Social Work Education 18(2): 121-132 
Bourner, T., (2003) Assessing reflective learning. Education + Training, Vol. 45 (5): 267-272 http://dx.doi.org/10.1108/00400910310484321

British Association of Counselling and Psychotherapy (2014). Applying for accreditation as a Counsellor/Psychotherapist - a guide for members.

http://www.bacp.co.uk/admin/structure/files/pdf/13682 guide\%20to\%20applying\%20jul14 . $\mathrm{pdf}$

British Association of Counselling and Psychotherapy (2016) Ethical Framework http://www.bacp.co.uk/admin/structure/files/pdf/14489 ethical-framework-jun15$\underline{\text { mono.pdf }}$

Coward, M. (2011). Does the use of reflective models restrict critical thinking and therefore learning in nurse education? What have we done? Nurse Education Today, 31(8), 883-886. doi:http://dx.doi.org/10.1016/j.nedt.2011.01.012

Dewey, J. (1933). How we think. Reprinted 2007. Stillwell, KS:Digireads.com Publishing Department of Health (2012) Compassion in practice. London, United Kingdom: DH

Fook, J. \& Askeland, G.A. (2007) Challenges of Critical Reflection: 'Nothing Ventured, Nothing Gained', Social Work Education, 26:5, 520-533, DOI: 10.1080/02615470601118662

Francis, R. (2010) Independent inquiry into care provided by Mid Staffordshire NHS Foundation Trust. January 2005 - March 2009. London, United Kingdom: DH Hassani, P., Abdi, A., \& Jalali, R. (2016). State of science. Intuition in nursing practice: A systematic review study. Journal of Clinical and Diagnostic Research. 2016 Feb, 10(2):7-11. DOI: $10.7860 / J C D R / 2016 / 17385.7260$

Health and Care Professions Council (2016) Revised Standards of Conduct, Performance and Ethics

http://www.hcpc-uk.org/publications/standards/index.asp?id=38 
Mezirow, J. (1997) Transformative learning: Theory to practice. New directions for adult and continuing education. No. 74 Summer 1997: 5-12

Mezirow, J. (1998) On critical reflection. Adult Education Quarterly. Spring 98 48(3): 185199

Moon, J.A. (2004) A handbook of reflective and experiential learning: Theory and Practice. London, UK: RoutledgeFalmer

Nelson, S. (2012) The lost path to emancipatory practice: Towards a history of reflective practice in nursing. Nursing Philosophy (2012), 13, 202-213

Nursing and Midwifery Council (2015) http://revalidation.nmc.org.uk/

Rolfe, G. (2014) Editorial: Educating the good-for-nothing student. Journal of Clinical Nursing, 23, 1459-1460

Saul, J.R. (2001) On equilibrium. Toronto, Canada: Penguin

Scammell, J. (2015). Making a connection: the key to humanised care. British Journal of Nursing, 2015, 24(15):786

Schön, D. A., \& Argyris, C. (1974) Theory in practice: How professionals think in action. San Francisco, USA: Jossey-Bass

Schön, D.A. (1983) The reflective practitioner. San Francisco, USA: Jossey-Bass

Walsh, K.D. (2007). On equilibrium: reflections on practice development and the philosophy of John Ralston Saul. Nursing Philosophy (2007), 8: 201-209 